\title{
Ultrathin, Ultrasmooth Gold Layer on Dielectrics without the Use of Additional Metallic Adhesion Layers
}

\author{
Leandro, Lorenzo; Malureanu, Radu; Rozlosnik, Noemi; Lavrinenko, Andrei
}

Published in:

A C S Applied Materials and Interfaces

Link to article, DOI:

10.1021/am508681u

Publication date:

2015

Document Version

Peer reviewed version

Link back to DTU Orbit

Citation (APA):

Leandro, L., Malureanu, R., Rozlosnik, N., \& Lavrinenko, A. (2015). Ultrathin, Ultrasmooth Gold Layer on Dielectrics without the Use of Additional Metallic Adhesion Layers. A C S Applied Materials and Interfaces, 7(10), 5797-5802. https://doi.org/10.1021/am508681u

\section{General rights}

Copyright and moral rights for the publications made accessible in the public portal are retained by the authors and/or other copyright owners and it is a condition of accessing publications that users recognise and abide by the legal requirements associated with these rights.

- Users may download and print one copy of any publication from the public portal for the purpose of private study or research.

- You may not further distribute the material or use it for any profit-making activity or commercial gain

- You may freely distribute the URL identifying the publication in the public portal 
Ultrathin, ultrasmooth gold layer on dielectrics

without the use of additional metallic adhesion layers • December 9, 2014

\title{
Ultrathin, ultrasmooth gold layer on dielectrics without the use of additional metallic adhesion layers
}

\author{
Lorenzo Leandro, Radu Malureanu, Noemi Rozlosnik, Andrei Lavrinenko \\ Technical University of Denmark \\ s131248@student.dtu.dk, rmal@fotonik.dtu.dk
}

Abstract

\begin{abstract}
With the advance in the plasmonics and metamaterials research field, it became more and more important to fabricate, thin and smooth Au metal films in a reliable way. Here, by thin films we mean that their average is height below $10 \mathrm{~nm}$ and their average roughness is below 5\% of the total thickness. In this article, we investigated the use of amino- and mercapto-silanes to increase the adhesion of Au on Si wafers thus obtaining a smooth and thin layer. This method do not include the uses of other metals to improve the adhesion of gold, like Ti or Cr, since they would reduce the optical characteristics of the structure. Our results show that layers having $6 \mathrm{~nm}$ thickness and below $0.3 \mathrm{~nm}$ roughness can be reproducibly obtained using amino-silanes. Layers having a nominal thickness of $5 \mathrm{~nm}$ have a yield of $50 \%$ thus this thickness is the limit for the process that we investigated.
\end{abstract}

\section{INTRODUCTION}

$\mathrm{T}$ He possibility of having $10 \mathrm{~nm}$ layers of metal on a substrate is a research topic widely studied [1, 2, 3]. It would be useful in several applications such as of plasmonic waveguides [4] or hyperbolic metamaterials [5]. Ultrathin, ultrasmooth metal layer on dielectrics can allow us to increase the band of use of hyperbolic meta-materials and can highly increase propagation of surface plasmon polaritons (SPPs) through the structure [6, 7], thus bringing this field closer to the large-scale implementation level. The main parameters to be considered for improving the functionality are roughness, thickness and optical proprieties of the metal.

The objective of this work is to investigate the possibility of improving the adhesion of gold on silicon oxide in order to decrease the thickness of the layer of metal on the dielectric substrate. The deposition of Au on silicon or oxidized substrates follows the Volmer-Weber growth mode, thus creating a perfect layer only over a certain thickness through clusters that connect to each other. A reduction of this lower limit for the thickness can be achieved by improving the adhesion between $\mathrm{Au}$ and the substrate. The current value for this limit is between 10 and $15 \mathrm{~nm}$ [8, 9]. The usual approach for adhesion improvement is using Ti or Cr layers. The addition of other metals decreases the optical properties of the layer and this effect is more evident for thin films since the ratio between $\mathrm{Au}$ and the other metal increase. In this work we analyse a way to increase the adhesion of gold that does not include the use of other metals.

This study analyses the adhesion given by various organosilane chemicals [10, 11, 12]. These organosilanes bind to the silicon surface by hydrolysis and condensation of silane creating covalent bonds on the surface. Linked to silane, a carbon chain connects the substrate with a radical. Different radicals were evaluated and their quality as adhesion promoters for gold was analysed. Furthermore, we studied the deposition of various thickness of gold with different deposition rates. We made the latter investigation in order to establish the lower limit for the thickness. The layer quality was investigated using scanning electron 
Ultrathin, ultrasmooth gold layer on dielectrics without the use of additional metallic adhesion layers • December 9, 2014

microscopy (SEM), atomic force microscopy (AFM) and four-point probe techniques. Although there are tests [13] showing improvement of gold adhesion on silica by using aminosilanes, the limits of Au deposition and a comparison with mercapto-silanes have not been yet investigated, to our knowledge.

\section{MethodS}

The surface treatment consists in immersing a silicon wafer in a solution of $95 \%$ of Isopropyl Alcohol, $2.5 \%$ of water and $2.5 \%$ of silane for three hours [14, 15, 16, 13]. We performed several tests to find the optimum immersion time. Less than three hours would not allow the chemical to react properly with the surface, inducing less adhesion promotion and thus rougher metal layer (not shown). More time would not help to improve the adhesion effect but will increase the amount of polimered silane thus altering the surface layer quality. For this reason we recommend not to leave the wafer in the solution for more than three hours and also to use more solution than needed to just cover the whole wafer. Indeed, the polimered silane seems to accumulate in the upper part of liquid, so having more mixture and keeping the wafer in the lower part of the beaker will result in a cleaner wafer.

We tested four different chemicals, all purchased from Sigma-Aldrich:

- (3-Mercaptopropyl)trimethoxysilane, $\mathrm{HS}\left(\mathrm{CH}_{2}\right)_{3} \mathrm{Si}\left(\mathrm{OCH}_{3}\right)_{3}, 95 \%$;

- (3-(2-Aminoethylamino)propyl)trimethoxysilane, $\left(\mathrm{CH}_{3} \mathrm{O}\right)_{3} \mathrm{Si}\left(\mathrm{CH}_{2}\right)_{3} \mathrm{NHCH}_{2} \mathrm{NH}_{2}, 80 \%$;

- (3-Aminopropyl)triethoxysilane, $\mathrm{H}_{2} \mathrm{~N}\left(\mathrm{CH}_{2}\right)_{3} \mathrm{Si}\left(\mathrm{OC}_{2} \mathrm{H}_{5}\right)_{3}, 99 \%$;

- (3-Aminopropyl)trimethoxysilane, $\mathrm{H}_{2} \mathrm{~N}\left(\mathrm{CH}_{2}\right)_{3} \mathrm{Si}\left(\mathrm{OCH}_{3}\right)_{3}, 97 \%$.

For reference, a standard silicon sample have been used.

The deposition of gold was made after the chemical treatment using an E-beam deposition system (deposition pressure $2-4 *$
$10^{-6} \mathrm{~Pa}$ ). We made several tests to understand how the deposition rate effects the surface quality and so the minimum thickness that creates a complete layer. We focused in maintaining the deposition rate as stable as possible and we compares the resultant surface only if made during the same process, to reduce the impact of the uncertainty in the deposition. Thickness from 4 to $10 \mathrm{~nm}$ and deposition rates from 5 to $13 \AA / s$ were evaluated.

We have investigated the surfaces after the gold deposition by SEM in order to see the quality and the completeness of the deposited layers. All the images presented show the typical surface of the sample, with a EHT of $5 \mathrm{kV}$, a magnification of 175,000 and a working distance between 2 and $4 \mathrm{~mm}$. Roughness and thickness measurements were done using AFM. The metal thickness measure comes with higher uncertainties due to the length and positioning of silane on the surface. The sheet resistance has been measured by four point probe measurements. Each sample was measured ten times in different areas and the average and standard deviation of the sheet resistance were calculated.

\section{Results}

A first test was performed for deciding the best silane to be used. From the images shown in fig. 1 . with $6 \mathrm{~nm}$ of gold deposited at $9.5 \AA / s$ we were able to see an improvement of the adhesion of the metal on the substrate for all four silanes used, compared with the untreated silicon case. The images regarding the (3(2-Aminoethylamino)propyl)trimethoxysilane were excluded since they showed results much worse than other chemicals, even if it was still acting as adhesion promoters. This is probably due to the presence of two amino groups, one of which is placed in the middle of the carbon chain.

The presence of voids in the silicon case is much clearer than in the others, but still some are visible on both the (3- 
Ultrathin, ultrasmooth gold layer on dielectrics without the use of additional metallic adhesion layers • December 9, 2014

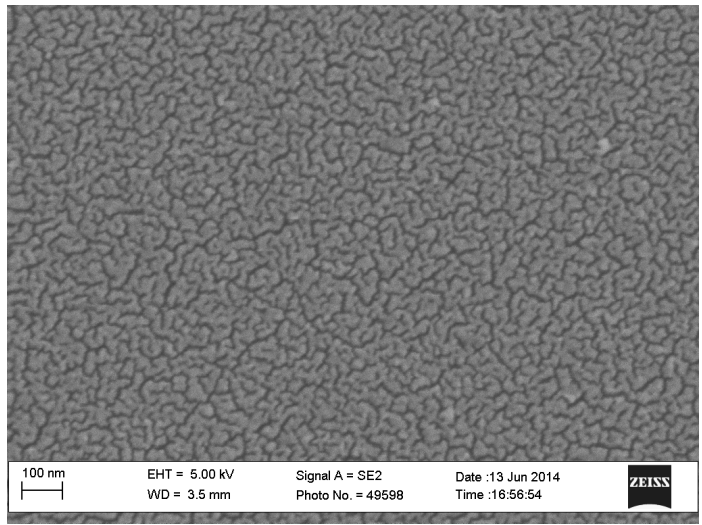

(a)

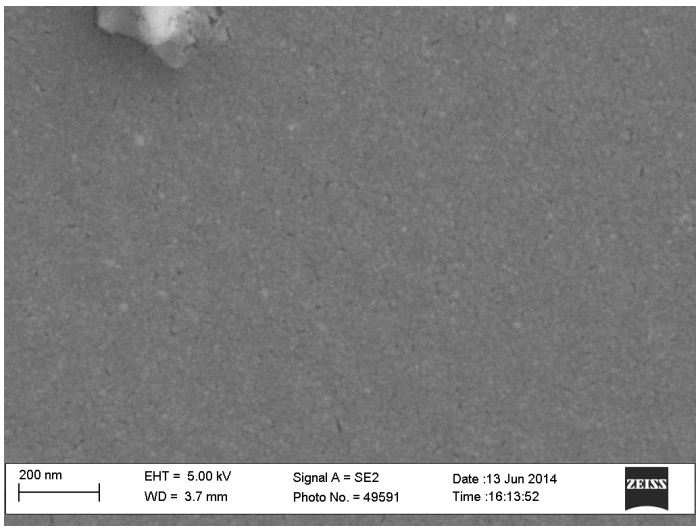

(c)

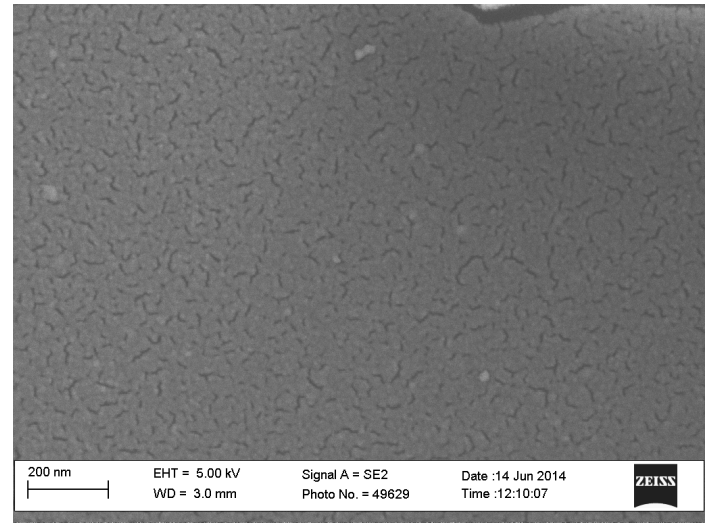

(b)

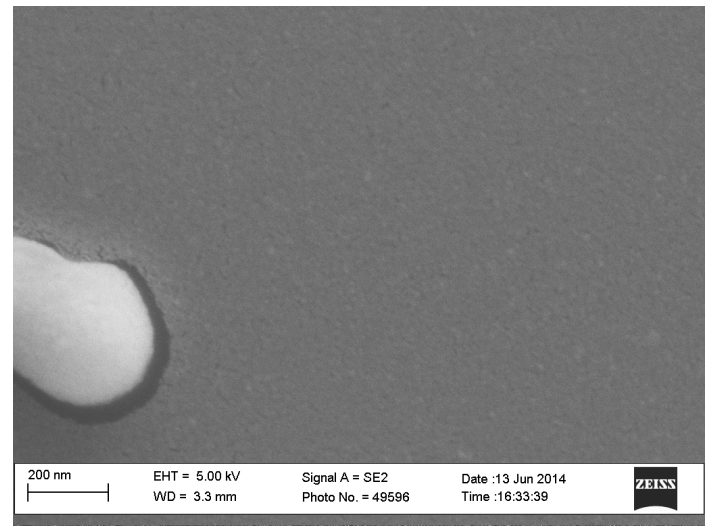

(d)

Figure 1: Images taken using the SEM of samples on which $6 \mathrm{~nm}$ of gold have been deposited with a rate of $9.5 \AA / s$ on Si (a); and after a treatment with (3-Mercaptopropyl)trimethoxysilane (b); (3-Aminopropyl)triethoxysilane (c); (3-Aminopropyl)trimethoxysilane (d). 
Ultrathin, ultrasmooth gold layer on dielectrics without the use of additional metallic adhesion layers • December 9, 2014

Mercaptopropyl)trimethoxysilane and the (3(2-Aminoethylamino)- propyl)trimethoxysilane (not shown) treated samples. On the other hand, complete layers are shown on the (3-Aminopropyl)triethoxysilane and the (3Aminopropyl)trimethoxysilane treated samples. We kept the Amino-silanes for further analysis.

Analysing surfaces treated with the same chemicals but with gold deposited at different rates, between 5 and $13 \AA / s$ (maximum rate for our machine), we were able to prove that increasing the deposition rate the surface quality also increases. This effect is shown in fig. 2 . where we can see two samples, treated with the same chemical have been covered by gold at different deposition rates.

Analysis using thinner layers proved inconclusive in deciding a difference between the $\mathrm{Au}$ layers deposited on these Amino-silanes. We decided to use (3Aminopropyl)trimethoxysilane for the last analysis, since it is more chemically stable.

To be noted the deposited adhesion promoter is reactive, thus the Au deposition should be done as soon as possible after the surface treatment. We had a huge decrease of the adhesion promotion for gold deposited after three or five days after the treatment, compared with the ones deposited just after or shortly after the surface treatment.

A sample on which $6 \mathrm{~nm}$ of gold was deposited at a rate of $9.5 \AA / s$ was used for the roughness analysis. The results in fig. 3 show a surface roughness below $0.26 \mathrm{~nm}$ with an RMS of $0.19 \mathrm{~nm}$.

Further analysis was made using (3Aminopropyl)trimethoxysilane, depositing $5 \mathrm{~nm}$ of gold with a rate of $13 \AA / s$ on four set of four samples each. For each set we run a deposition process, using always the same parameters. The resultant images show that $5 \mathrm{~nm}$ can be considered the "critical point" for the gold deposition.
We see, in the example in fig. 4 , that a deposition of $5 \mathrm{~nm}$ of gold cannot create a complete layer in a reproducible manner. We found that the quality of the surfaces is good enough to be considered a layer in about $58 \%$ of the cases: 7 out of 12 samples showed the surface covered by a continuous layer of gold.

Due to the combination of a small thickness and fast deposition rate, we have uncertainties in the deposited thickness. Our AFM measurements show a total thickness between 6.0 and $6.8 \mathrm{~nm}$ for a $5 \mathrm{~nm}$ deposition. Considering that the silane carbon chains has a length of $0.8 \mathrm{~nm}$ [17], we have a discrepancy between 0.2 and $1 \mathrm{~nm}$. We believe this discrepancy to arise from the uncertainties on the deposited thickness as well as from the layer roughness. As shown in table1, we saw high roughness values $(22 \mathrm{~nm})$ for the $4 \mathrm{~nm}$ thick gold sample, with a maximum height difference of $190 \mathrm{~nm}$. Much lower values for the other samples mean that the roughness decrease rapidly increasing the thickness from 4 to $5 \mathrm{~nm}$, showing that the surface quality has a fast increase. Also, in table 1 are shown the average resistivity and its standard deviation calculated from ten measurements for each sample. The resistivity values have to be compared with the ones estimated from the Drude model for thin gold films.

Based on [18] we calculated the gold resistivity in the long wavelength limit. Thus, for $\lambda \rightarrow \infty$, the resistivity becomes

$$
\rho=\frac{\Gamma(r)}{w_{p}^{2} \varepsilon_{0}}
$$

where $\Gamma(r)$ is the size-dependent damping frequency and $\omega_{p}$ is the plasma frequency. To be noted that for bulk gold, thus when $r \rightarrow \infty$, $\Gamma(r)$ becomes $\Gamma_{-}$. In this case, the bulk gold resistivity is $19.5 n \Omega m$ (for further information about the notations refer to [18]). This value is underestimated with respect to the one found in literature, of $24.4 n \Omega m$ [19] thus we believe that the calculated values of resistivity also for thin films are slightly underestimated. This fact might easily explain the discrepancy in table 1 where the measured resistivity value is 
Ultrathin, ultrasmooth gold layer on dielectrics without the use of additional metallic adhesion layers • December 9, 2014

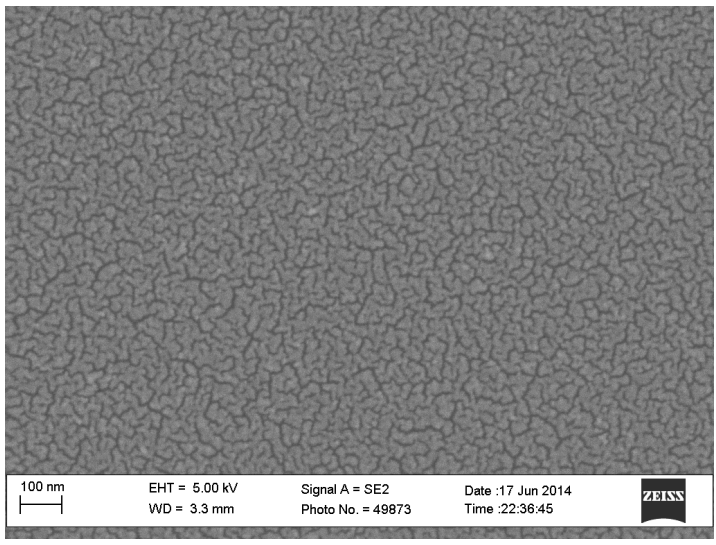

(a)

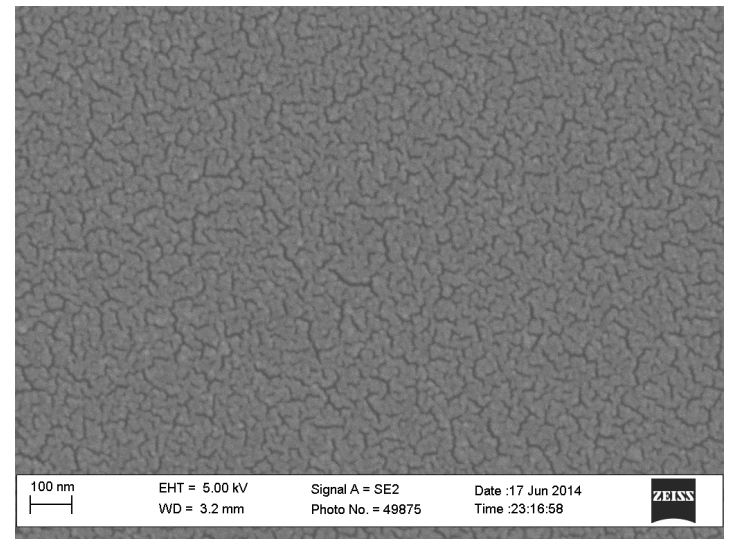

(b)

Figure 2: Images taken using the SEM of samples on which $5 \mathrm{~nm}$ of gold have been deposited with a rate of (a) $5 \AA / \mathrm{s}$ and (b) $10 \AA / s$ after a treatment with (3-Aminopropyl)trimethoxysilane, on a silicon substrate.

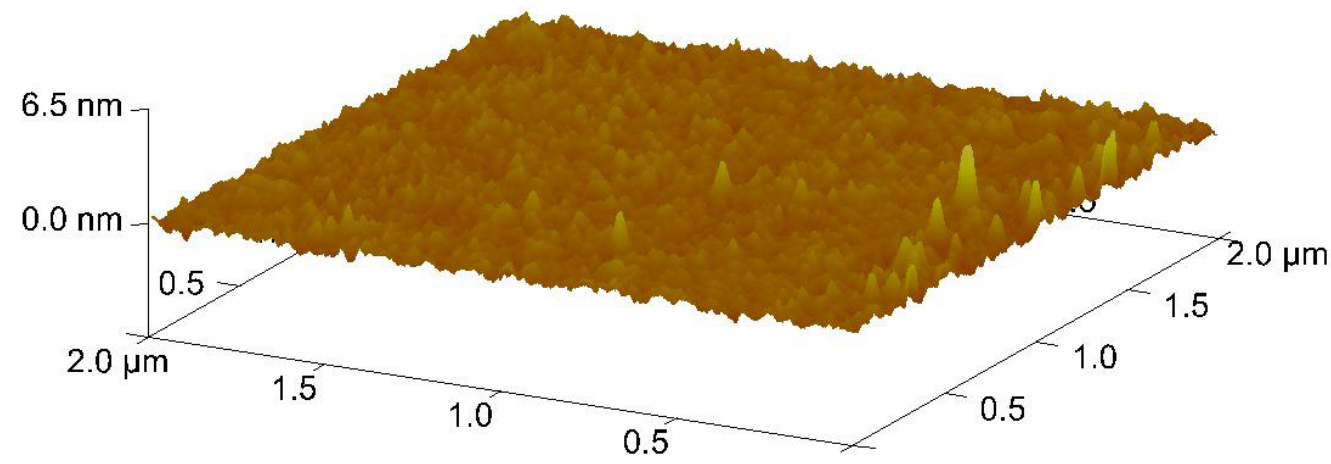

Figure 3: Pictures taken using the AFM of a sample on which $6 \mathrm{~nm}$ of gold have been deposited with a rate of $9.5 \AA / \mathrm{s}$ after a treatment with (3-Aminopropyl)trimethoxysilane.

\begin{tabular}{|c|c|c|c|c|c|c|}
\hline Thickness & $\begin{array}{c}\text { Estimated } \\
\text { Resistivity } \\
{[n \Omega m]}\end{array}$ & $\begin{array}{c}\text { Average } \\
\text { Resistivity } \\
{[n \Omega m]}\end{array}$ & $\begin{array}{c}\text { Standard } \\
\text { Deviation } \\
{[n \Omega m]}\end{array}$ & Roughness & $\begin{array}{c}\text { Root Mean } \\
\text { Square } \\
{[n m]}\end{array}$ & $\begin{array}{c}\text { Maximum } \\
\text { Height } \\
{[n m]}\end{array}$ \\
\hline 4 & 219.7 & 1840.8 & 74.4 & 17.4 & 22 & 190 \\
\hline 5 & 179.6 & 326.4 & 14.0 & 0.60 & 0.75 & 6.89 \\
\hline 6 & 152.9 & 106.9 & 2.22 & 0.19 & 0.26 & 4.55 \\
\hline
\end{tabular}

Table 1: Estimated resistivity for thin gold films calculated from [18]; the average resistivity and its standard deviation calculated from ten measurements, for each sample, made with a four probe method; the roughness, its root mean square and its peak-to-valley maximum value. The considered samples are covered by 4, 5 and $6 \mathrm{~nm}$ of gold, respectively, deposited at $9.5 \AA / s$. 
Ultrathin, ultrasmooth gold layer on dielectrics without the use of additional metallic adhesion layers • December 9, 2014

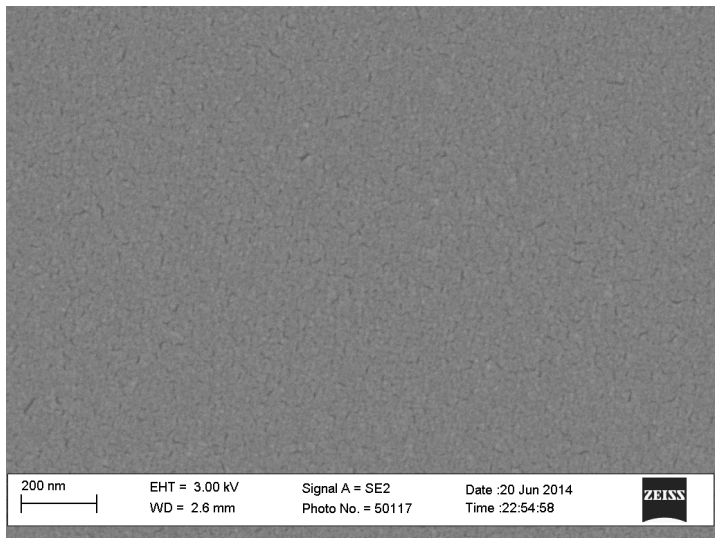

(a)

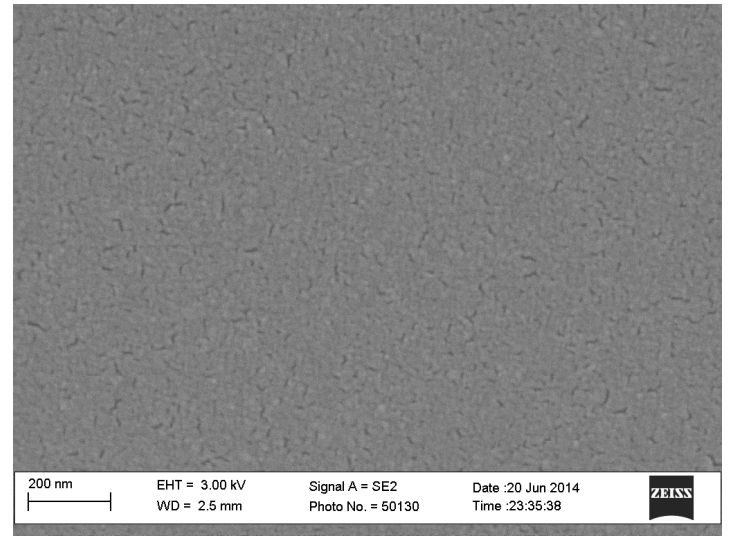

(b)

Figure 4: Pictures taken using the SEM of two samples, made in different processes, on which $5 \mathrm{~nm}$ of gold have been deposited with a rate of $13 \AA / s$ using the Alcatel SCM 600 E-beam and sputtering deposition system, after a treatment with (3-Aminopropyl)trimethoxysilane. (a) sample n.2, set 1, considered a layer; $(b)$ sample n.2, set 2, not considered a layer.

smaller than the estimated one in the case of the $6 \mathrm{~nm}$ thick layer.

\section{Conclusion}

We have been able to reproducibly deposit a complete gold layer of $6 \mathrm{~nm}$ thick on a silica surface. The adhesion was improved by treating the surface with (3Aminopropyl)trimethoxysilane. Different silanes were compared with an untreated silicon sample and they proved to act as adhesion promoters. Amino-silanes showed better results compared with Mercapto-silanes. We showed that the increase in deposition rate improves the surface quality and lower the minimum thickness imit. The thickness measurement, together with the surface quality check and the four probe resistivity measurement, demonstrated that it is possible to deposit a good-quality gold layer of thickness as low as $5 \mathrm{~nm}$. Finally, roughness measurements showed low average roughness below $0.2 \mathrm{~nm}$ with $0.3 \mathrm{~nm}$ RMS.

\section{REFERENCES}

[1] Nadia Formica, Dhriti S. Ghosh, Albert Carrilero, Tong Lai Chen, Robert E. Simpson, and Valerio Pruneri. Ultrastable and atomically smooth ultrathin silver films grown on a copper seed layer. ACS APPLIED MATERIALS and INTERFACES, 5(8):3048-3053, 2013. ISSN 19448244, 19448252. doi: $10.1021 / \mathrm{am} 303147 \mathrm{w}$.

[2] D. R. Smith, Willie J. Padilla, D. C. Vier, S. C. Nemat-Nasser, and S. Schultz. Composite medium with simultaneously negative permeability and permittivity. Phys. Rev. Lett., 84:4184-4187, May 2000. doi: 10.1103/PhysRevLett.84.4184.

[3] N. Fang, H. Lee, C. Sun, and X. Zhang. Sub-diffraction-limited optical imaging with a silver superlens. SCIENCE, 308 (5721):534-537, 2005. ISSN 00368075, 10959203. doi: 10.1126/science.1108759.

[4] Jong Hyuk Park, Palak Ambwani, Michael Manno, Nathan C. Lindquist, Prashant Nagpal, Sang-Hyun Oh, Chris Leighton, and David J. Norris. Single-crystalline silver films for plasmonics. ADVANCED MATERIALS, 24(29):3988-3992, 2012. ISSN 
Ultrathin, ultrasmooth gold layer on dielectrics without the use of additional metallic adhesion layers • December 9, 2014

09359648, 15214095. doi: 10.1002/adma. 201200812.

[5] Omar Kidwai, Sergei V. Zhukovsky, and J. E. Sipe. Effective-medium approach to planar multilayer hyperbolic metamaterials: Strengths and limitations (12 pages) 053842. Physical Review - Section a - Atomic Molecular and Optical Physics, 85(5), 2012. ISSN 10502947, 10941622.

[6] Prashant Nagpal, Nathan C. Lindquist, Sang Hyun Oh, and David J. Norris. Ultrasmooth patterned metals for plasmonics and metamaterials. Science, Science, 325(5940):594-597, 2009. ISSN 10959203, 00368075. doi: 10.1126/science.1174655.

[7] D. Sarid. Long-range surface-plasma waves on very thin metal-films. PHYSICAL REVIEW LETTERS, 47(26):1927-1930, 1981. ISSN 00319007, 10797114.

[8] A. Hammiche, R. P. Webb, and I. H. Wilson. A scanning tunnelling microscopy study of thin gold films evaporated on silicon. VACUUM -LONDON THEN OXFORD- PERGAMON-, 45(5):569, 1994. ISSN 0042-207X.

[9] Petr Malinský, Petr Slepička, Vladimír Hnatowicz, and Václav Svorčík. Early stages of growth of gold layers sputter deposited on glass and silicon substrates. Nanoscale research letters, 7:241, 2012. ISSN 1556-276X. doi: 10.1186/1556-276X-7-241.

[10] TE Gentle, RG Schmidt, BM Naasz, AJ Gellman, and TM Gentle. Organofunctional silanes as adhesion promoters: direct characterization of the polymer silane interphase. JOURNAL OF ADHESION SCIENCE AND TECHNOLOGY, 6(2):307316, 1992. ISSN 01694243, 15685616.

[11] M.C. Polniaszek and R.H. Schaufelberger. Improving adhesives with silane adhesion promoters. Adhesives Age, 11(7):25-27, 1968. ISSN 0001821x.

[12] A. Doron, E. Katz, and I. Willner. Organization of au colloids as monolayer films onto ito glass surfaces: application of the metal colloid films as base interfaces to construct redox-active monolayers. LANGMUIR, 11(4):1313-1317, 1995. ISSN 07437463, 15205827.

[13] DFS Petri, G. Wenz, P. Schunk, and T. Schimmel. An improved method for the assembly of amino-terminated monolayers on sio2 and the vapor deposition of gold layers. LANGMUIR, 15(13):45204523, 1999. ISSN 07437463, 15205827. doi: 10.1021/la981379u.

[14] Abraham Ulman. Formation and Structure of Self-Assembled Monolayers. Chemical Reviews, 96(4):1533-1554, January 1996. ISSN 0009-2665. doi: 10.1021/cr9502357.

[15] Henriette Baun Madsen, Helle M ArboeAndersen, Noemi Rozlosnik, Flemming Madsen, Peter Ifversen, Marina R Kasimova, and Hanne Mør rck Nielsen. Investigation of the interaction between modified ISCOMs and stratum corneum lipid model systems. Biochimica et biophysica acta, 1798(9):1779-89, September 2010. ISSN 0006-3002. doi: 10.1016/j.bbamem. 2010.06.006.

[16] John A. Howarter and Jeffrey P. Youngblood. Optimization of silica silanization by 3-aminopropyltriethoxysilane. LANGMUIR, 22(26):11142-11147, 2006. ISSN 07437463, 15205827. doi: 10.1021/ la061240g.

[17] Myungsook Kim, Fevzihan Basarir, Jiwoong Park, Tae-Ho Yoon, and Yun Hee Jang. Computational calculation of thickness of self-assembled monolayer of 3-aminopropyltriethoxysilane on quartz (100).

[18] Joshua A. Gordon and Richard W. Ziolkowski. The design and simulated performance of a coated nano-particle laser. OPTICS EXPRESS, 15(5):2622-2653, 2007. ISSN 10944087. doi: 10.1364/OE.15. 002622. 
Ultrathin, ultrasmooth gold layer on dielectrics without the use of additional metallic adhesion layers • December 9, 2014

[19] R. Serway and J. Jewett. Principles of Physics: A Calculus-Based Text. Number v. 1. Cengage Learning, 2005. ISBN 9780534491437.

[20] Alberto F. Scarpettini and Andrea V. Bragas. Coverage and aggregation of gold nanoparticles on silanized glasses. LANGMUIR, 26(20):15948-15953, 2010. ISSN 07437463, 15205827. doi: 10.1021/ la102937b.

[21] Jeonghyeon Yang, Takashi Ichii, Kuniaki Murase, and Hiroyuki Sugimura. Siteselective assembly and reorganization of gold nanoparticles along aminosilanecovered nano lines prepared on indiumtin oxide. LANGMUIR, 28(20):7579-7584, 2012. ISSN 07437463, 15205827 doi: 10.1021/la301042y.
[22] Kosuke Yamashiro, Kuniaki Murase, Takashi Ichii, Shihang Mo, and Hiroyuki Sugimura. Photochemical assembly of gold nanoparticle arrays covalently attached to silicon surface assisted by localized plasmon in the nanoparticles. Journal of Physical Chemistry C, 117(6):24802485, 2013. ISSN 19327447, 19327455. doi: 10.1021/jp306290w.

[23] Chi-Fan Chen, Shien-Der Tzeng, MengHsien Lin, and Shangjr Gwo. Electrostatic assembly of gold colloidal nanoparticles on organosilane monolayers patterned by microcontact electrochemical conversion. LANGMUIR, 22(18):7819-7824, 2006. ISSN 07437463, 15205827. doi: 10.1021/ la060656r. 